\title{
Quantitative evaluation of macrophage aggregates in brook trout Salvelinus fontinalis and rainbow trout Oncorhynchus mykiss
}

\author{
Adam R. Schwindt ${ }^{1, *}$, Nathan Truelove ${ }^{2}$, Carl B. Schreck ${ }^{2,3}$, John W. Fournie ${ }^{4}$, \\ Dixon H. Landers ${ }^{5}$, Michael L. Kent ${ }^{1}$ \\ ${ }^{1}$ Department of Microbiology, Center for Fish Disease Research, 220 Nash Hall, Oregon State University, Corvallis, \\ Oregon 97331-3804, USA \\ ${ }^{2}$ Department of Fisheries and Wildlife, 104 Nash Hall, Oregon State University, Corvallis, Oregon 97331-3803, USA \\ ${ }^{3}$ Oregon Cooperative Fish and Wildlife Research Unit-USGS Biological Resources Division, 104 Nash Hall, \\ Oregon State University, Corvallis, Oregon 97331-3803, USA \\ ${ }^{4}$ US EPA, National Health and Environmental Effects Research Laboratory, Gulf Ecology Division, 1 Sabine Island Drive, \\ Gulf Breeze, Florida 32561, USA \\ ${ }^{5}$ US EPA, National Health and Environmental Effects Research Laboratory, Western Ecology Division, 200 SW 35th Street, \\ Corvallis, Oregon 97333, USA
}

\begin{abstract}
Macrophage aggregates (MAs) occur in various organs of fishes, especially the kidney, liver and spleen, and contain melanin, ceroid/lipofuscin and hemosiderin pigments. They have been used as indicators of a number of natural and anthropogenic stressors. Macrophage aggregates occur in salmonids but are poorly organized, irregularly shaped, and are generally smaller than those in derived teleosts. These features complicate quantification, and thus these fishes have seldom been used in studies correlating MAs with environmental stressors. To alleviate these complications, we developed color filtering algorithms for use with the software package ImagePro Plus ${ }^{\circledR}$ (Media Cybernetics) that select and quantify pigmented area (i.e. colors ranging from gold to brown to black) in tissue sections. Image analysis results compared well with subjective scoring when tested on brook trout Salvelinus fontinalis and rainbow trout Oncorhynchus mykiss captured from high-elevation lakes or hatcheries. Macrophage aggregate pigments correlated positively with age and negatively with condition factor. Within individual fish, pigmentation correlated positively among organs, suggesting that the kidney, liver or spleen are suitable indicator organs. In age-matched fishes, MA pigments were not different between hatcheries and lakes in the organs examined. Between lakes, differences in pigments were observed in the kidney and spleen, but were not explained by age, condition factor, sex or maturation state. Our results indicate that quantification of the area occupied by MA pigments is an efficient and accurate means of evaluating MAs in salmonid organs and that organ pigmentation correlates with age and condition factor, as seen in studies with more derived fishes.
\end{abstract}

KEY WORDS: Macrophage aggregates · Brook trout $\cdot$ Rainbow trout $\cdot$ Fishes $\cdot$ Pigment $\cdot$ Ecotoxicology . Stress

Resale or republication not permitted without written consent of the publisher

\section{INTRODUCTION}

Macrophage aggregates (MAs) are focal accumulations of pigmented macrophages occurring primarily in hematopoietic and hepatic tissues of poikilothermic animals, particularly teleost fishes (Wolke 1992, Agius
\& Roberts 2003). They can also occur in other organs including gonads of fishes captured from degraded environments (Blazer 2002, Patiño et al. 2003). Melanin, hemosiderin and ceroid/lipofuscin are the pigments contained within the MAs and range in color from gold to brown to black in hematoxylin and eosin 
stained slides (Wolke 1992, Agius \& Roberts 2003). Increases in pigment content are suggestive of catabolic, infectious, toxic or otherwise stressful events or exposures (Wolke 1992, Agius \& Roberts 2003).

In the more ancestral teleosts, such as the Clupeiformes and Salmoniformes, MAs are more difficult to define because they are poorly organized, irregularly shaped and smaller compared to the more derived fishes, which possess discrete aggregations (Wolke 1992, Agius \& Roberts 2003). These differences in MA morphology between the ancestral and derived fishes lead to ambiguity when MA data are reported as numbers $\mathrm{mm}^{-2}$ or mean size, because the definition of a MA is critical. For example, Fournie et al. (2001) determined that $>40$ splenic MAs $\mathrm{mm}^{-2}$ in the 7 species they examined were indicative of exposure to a degraded environment. However, Agius \& Roberts (1981) reported splenic MAs numbering $800 \mathrm{~mm}^{-2}$ in rainbow trout Oncorhynchus mykiss after 10 wk of starvation. Considering the difficulties with defining and counting MAs in salmonids, we hypothesize that the area occupied by MA pigments can substitute for MA counts and be calculated from computerized image analysis.

MA pigment quantification has been performed by others. Splenic hemosiderin was quantified by Kranz (1989), Bucke et al. (1992) and Khan \& Nag (1993), and Mizuno et al. (2002) quantified melanin in the kidney interstitium in masu salmon Oncorhynchus masou.

MA are stimulated by the presence of cellular byproducts or noxious foreign materials, often occurring with some form of stressor such as poor nutrition, parasitic or bacterial infection, hemolysis or anthropogenic contamination. MAs increase in number with age and are negatively correlated with condition factor (K)
(Agius 1981, Brown \& George 1985, Blazer et al. 1987). Blazer et al. (1987) used MAs as an indicator of environmental stress, and MAs increase with starvation (Agius \& Roberts 1981, Mizuno et al. 2002). Pathogens induce MAs, particularly parasites associated with chronic, focal infections (Vogelbein et al. 1987). Fishes are used as sentinel species in ecotoxicology studies and the utility of MAs as a biomarker for non-specific contaminant exposure has been demonstrated in several studies (Khan \& Kiceniuk 1984, Pulsford et al. 1992, Blazer et al. 1994, 1997, Manera et al. 2000, Fournie et al. 2001, Blazer 2002, Patiño et al. 2003, Capps et al. 2004). This broad application of MAs for assessment of fish and environmental health has been well-documented in many fishes, but not for the salmonids.

The aims of this study were: (1) to develop a highthroughput, objective, and quantitatively rigorous method for calculating total MA pigments in salmonids; (2) to determine which organ is most appropriate for MA analysis; (3) to test if salmonid kidney, liver and spleen MAs correlate with age and K similar to the derived teleosts; and (4) to determine if any gender, sexual maturation, and hatchery or wild fish differences exist in MA accumulation.

\section{MATERIALS AND METHODS}

Fish collection. Fishes were captured from highelevation lakes or obtained from Oregon Department of Fish Wildlife fish hatcheries (Table 1). Brook trout Salvelinus fontinalis and rainbow trout Oncorhynchus mykiss were collected by angling from 5 lakes in 3

Table 1. Collection site (lakes in national parks [NP] or hatcheries), species, sample numbers, average age, condition factor (K), maturation stage and sex ratio in Salvelinus fontinalis and Oncorhynchus mykiss. Data are means \pm SEM. K: condition factor calculated as fork length, FL $\left(\mathrm{K}=\left[\right.\right.$ mass $\left.\left.(\mathrm{g}) \times \mathrm{FL}(\mathrm{mm})^{-3}\right] \times 100000\right]$. Stage: maturation stage determined in Van Eenennaam \& Doroshov (1998). N: no. of fish; na: not available

\begin{tabular}{|c|c|c|c|c|c|}
\hline Site location; elevation & $\mathrm{N}$ & Age $(y r)$ & $\mathrm{K}$ & Stage $(1-7)$ & Male:female \\
\hline \multicolumn{6}{|l|}{ S. fontinalis } \\
\hline $\begin{array}{l}\text { Emerald Lake Sequoia NP, } \\
36.58^{\circ} \mathrm{N}, 118.67^{\circ} \mathrm{W}_{i} 2800 \mathrm{~m}\end{array}$ & 15 & $5.3 \pm 0.42(2-8)$ & $0.91 \pm 0.03$ & $2.94 \pm 0.28$ & 1.7 \\
\hline $\begin{array}{l}\text { Pear Lake Sequoia NP, } \\
36.60^{\circ} \mathrm{N}, 118.67^{\circ} \mathrm{W}_{i} 2900 \mathrm{~m}\end{array}$ & 16 & $5.0 \pm 0.47(3-10)$ & $0.95 \pm 0.04$ & $2.71 \pm 0.24$ & 4.7 \\
\hline $\begin{array}{l}\text { Lone Pine Lake Rocky Mountain NP, } \\
40.22^{\circ} \mathrm{N}, 105.73^{\circ} \mathrm{W}_{;} 3024 \mathrm{~m}\end{array}$ & 15 & $3.9 \pm 0.52(2-8)$ & $0.99 \pm 0.04$ & $4.0 \pm 0.41$ & 0.88 \\
\hline $\begin{array}{l}\text { PJ Lake Olympic NP, } \\
47.95^{\circ} \mathrm{N}, 123.42^{\circ} \mathrm{W}_{i} 1433 \mathrm{~m}\end{array}$ & 15 & $4.7 \pm 0.52(1-7)$ & $1.02 \pm 0.02$ & $3.7 \pm 0.16$ & 0.36 \\
\hline $\begin{array}{l}\text { Wizard Falls Hatchery, } \\
\text { Camp Sherman, Oregon }\end{array}$ & 5 & $2.4 \pm 0.24(2-3)$ & na & na & na \\
\hline \multicolumn{6}{|l|}{ O. mykiss } \\
\hline $\begin{array}{l}\text { Mills Lake Rocky Mountain NP, } \\
40.29^{\circ} \mathrm{N}, 105.64^{\circ} \mathrm{W}^{\prime} 3030 \mathrm{~m}\end{array}$ & 15 & $4.25 \pm 0.51(1-8)$ & $1.18 \pm 0.03$ & $3.29 \pm 0.22$ & 0.75 \\
\hline Roaring River Hatchery, Scio, Oregon & 9 & $2.7 \pm 0.44(1-4)$ & na & na & na \\
\hline
\end{tabular}


western US national parks (NP) (Table 1) as part of a larger study investigating the effects of airborne contaminants on high-elevation and arctic aquatic ecosystems (Western Airborne Contaminants Assessment Project). At the high-elevation lakes, fish were landed within $30 \mathrm{~s}$ of hooking and up to 7 were placed in an 81 bucket filled with lake-water. Fresh lake-water was routinely added prior to euthanization. Within $30 \mathrm{~min}$ of capture, each fish was killed with a blow to the head. Hatchery fish were collected randomly from raceways by dip-net and killed by buffered tricaine methanesulfonate overdose (exact dose not specified).

Tissue processing and image analysis. All fishes were inspected externally and internally for gross abnormalities. Gender was determined, and fork length (FL) and mass were recorded and used to calculate the condition factor, $\mathrm{K}: \mathrm{K}=\left(\left[\operatorname{mass}(\mathrm{g}) \times \mathrm{FL}(\mathrm{mm})^{-3}\right] \times\right.$ $100000)$. At the lakes and hatcheries, small pieces of posterior kidney, liver, spleen and gonad samples were removed and fixed in $10 \%$ neutral buffered formalin and transported to the laboratory for histological examination. We collected samples from similar regions of the organs: posterior to the dorsal fin for the kidney, the middle of the spleen, and the posterior aspect of the liver. Sagittal otoliths from wild caught fish were removed in the field or the laboratory and stored in $70 \%$ ethyl-alcohol for age determination. Fishes were aged as described by Hall (1991). Age data for the hatchery fish were provided by the hatchery staff.

Posterior kidney, liver, spleen and gonad were processed for routine histological examination. We prepared 3 stepwise sections (50 $\mu \mathrm{m}$ separation) from all organs. Individual sections were $5 \mu \mathrm{m}$ thick and stained with hematoxylin and eosin. Kidney sections of 1 brook trout from Emerald Lake, Sequoia NP, with multiple granulomas were stained with either Gram or periodic acid Schiff (PAS) to identify possible microorganisms. We captured 2 non-overlapping digital images each from the first and last sections (100 $\mu \mathrm{m}$ total separation) at $200 \times$ final magnification for each organ with a Leica DMLB ${ }^{\circledR}$ compound light microscope equipped with a SPOT $\mathrm{RT}^{\circledR}$ color camera (Diagnostic Instruments) interfaced to an IBM compatible computer with SPOT RT ${ }^{\circledR}$ image capture software Version 3.0 (Diagnostic Instruments).

The gonads were staged for maturity, with methods modified from Van Eenennaam \& Doroshov (1998) developed for Atlantic sturgeon Acipenser oxyrhynchus, to test for potential MA differences in stage of maturation. The maturation stages in the male or female trout, respectively, were: (1) testis or ovarian differentiation; (2) spermatogonia proliferation or endogenous oocyte growth; (3) beginning meiosis or early vitellogenesis; (4) spermatogenesis or mid-vitellogenesis; (5) spermiated or migratory nucleus; (6) post-spermiated or post germinal vesicle breakdown; (7) post-ovulation (no corresponding male stage). The maturation stages were further grouped as immature $(1,2)$, maturing $(3,4)$, and mature (5 to 7 ) to increase statistical power when testing for differences in MAs between maturation groups within a given lake.

We employed 2 methods similar to those used by Fournie et al. (2001) to determine the extent of organ pigmentation. First, we subjectively categorized the relative area of pigment deposition in histological sections, represented by shades of colors ranging from gold to brown to black. The following scale was used to evaluate MA intensity: (0) few or no MAs; (1) <one-third occupied by MAs; (2) >one-third but <two-thirds occupied by MAs; (3) $\geq$ two-thirds occupied by MAs.

We then used computerized image analysis (ImagePro ${ }^{\circledR}$ Plus Version 5.1, MediaCybernetics) for quantitative evaluation of MAs in the 4 images captured from each organ. To automate pigment quantification, representative MAs were cut from a subset $(\sim 5 \%)$ of the 935 total images, assembled into a composite image for each organ, and pigments selected based on color. The pigment selection on the composite image was a template of colors, gold to brown to black (referred to as a 'color mask'), that the software used to automatically select the same colors in all images. This served to separate the MA pigments from the other cellular pigments (color filtering algorithm). The color filtering algorithm was then applied to the images, area of MA pigments was quantified per the total image area in pixels, and data were exported to a spreadsheet.

Some background pigment selection was detected, such as regions of black in individual macrophages with melanin pigment, melanocytes, or pyknotic nuclei. We measured these background objects (on average $10 \times 3$ pixels) and filtered them with a size exclusion parameter (the background selections were rarely circular). We removed individual macrophages from the final area occupied because these do not represent aggregates. Because aggregates are difficult to define in salmonids, $>2$ macrophages could be argued to comprise a MA. Furthermore, the aggregate itself is the physiological or immune response of interest, not the action of individual macrophages. Therefore, to be as consistent with the classic definition of a macrophage aggregate as possible, individual cells are not quantified. Area occupied by these cells is also very small with a negligible effect on the average pigmented areas.

Incorporated into the pigment selection was calculation of areas with no tissue resulting from post-mortem tissue fracture or small organ samples. This area void of tissue was removed from the total area of the image so that final percentages related only MA pigments to the normal tissue pigments by the following: corrected 
area $=\left[P_{\text {area }} \times(1-A V)^{-1}\right] \times 100 \%$, where $P_{\text {area }}=$ propor tion of image occupied by MA pigments, $A V=$ area void of tissue, and $(1-A V)^{-1}=$ fraction of the image occupied by tissue. After calculating the corrected area for each image of a given organ, the percentages were averaged because there were 4 images per organ.

Statistical analyses. All data were inspected for normality by visual examination of 'box-and-whisker' plots of the raw data. Extreme skewness was corrected for by transformation of the data where noted. A 1-way analysis of variance (ANOVA) was used to test for all between site differences. Fisher's least significant difference (LSD) measure was used as the post hoc test when a significant main effect was found. When comparing between lakes, only those with brook trout were compared to avoid interspecific variability. Gender comparisons within lakes and age-matched MA comparisons between hatchery and wild fishes were made by a Student's $t$-test. Initially, simple linear regression was used on the raw MA data to determine the relationship between MAs and age, $\mathrm{K}$, and maturation state. In all cases the MA data were arcsine square-root-transformed to improve the fit of the data. Statistical significance was set at $\mathrm{p}=0.05$.

\section{RESULTS}

\section{Subjective versus quantitative evaluations of MAs}

Comparison of the subjective evaluations with the results from the image analysis indicated that both methods yielded similar information for the kidney, liver and spleen. When the pigmented areas calculated from image analysis were grouped by subjective category, clear differences in mean pigmented area were observed between the low (0 and 1$)$ and the high (2 and 3) categories (Fig. 1). The subjective evaluations were performed on the entire tissue section while the quantitative evaluations were performed on subsets (images taken from 4 fields at $200 \times$ total magnification) of the tissue sections. Because the method we chose to subsample was representative of the entire tissue section, the quantitative analysis of the subsets agreed with the subjective analysis of the entire tissue section (Fig. 1). Image analysis was very efficient, with up to 150 images evaluated per day (1 to $10 \mathrm{~min}$ per image). Very few images $(<3 \%)$ required more than 2 min to analyze. This is about twice what would be possible by visual assessment. For quantitative evaluations, the color masks were highly sensitive at distinguishing between MA pigments and other cellular colors. This feature was especially important for distinguishing between the gold to yellow (ceroid/lipofuscin) and the light pink to
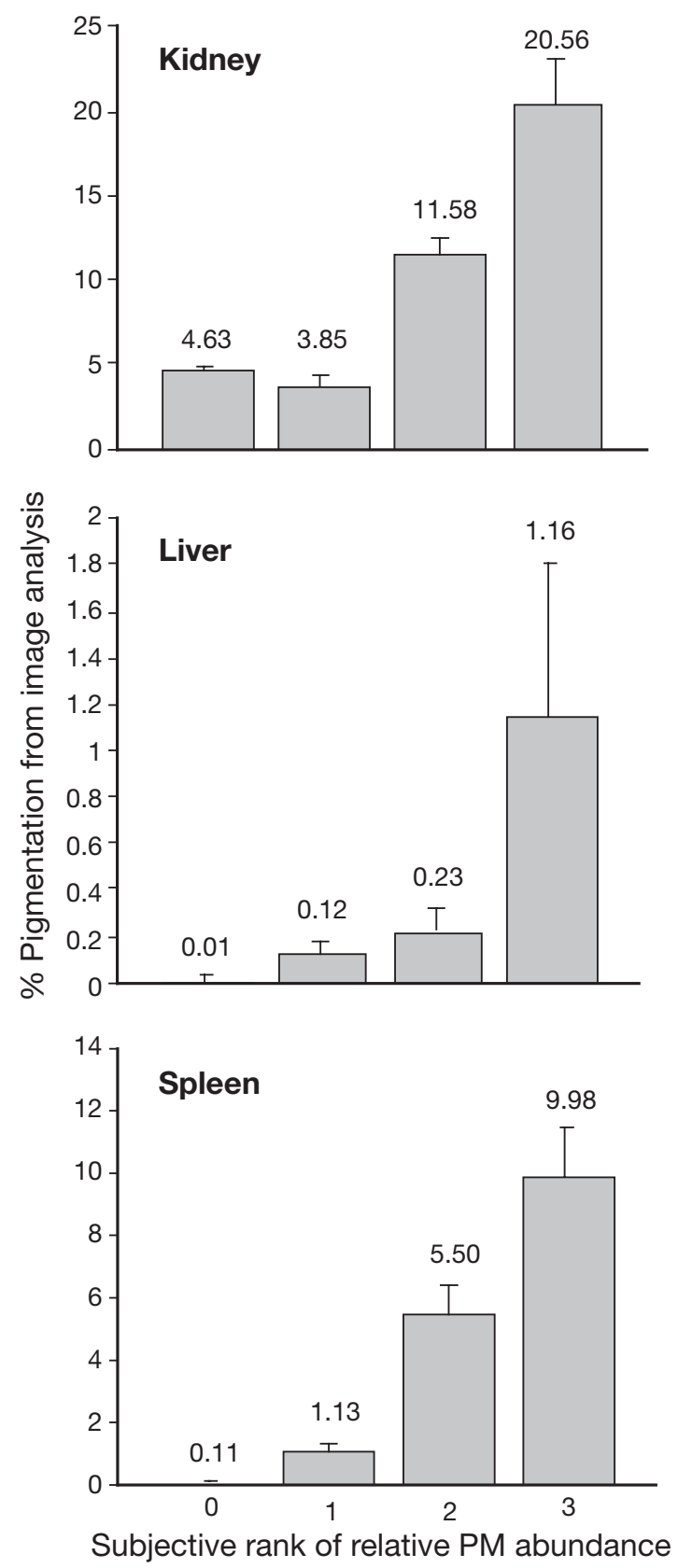

Fig. 1. Salvelinus fontinalis and Oncorhynchus mykiss. Quantitative versus subjective rank evaluation (see 'Materials and methods') of macrophage aggregate pigmentation (PM) in kidney, liver and spleen. Nos. above histograms are means; bars are + SEM

orange cytoplasm stained with eosin (Fig. 2). Furthermore, only a few images required adjustment of brightness, contrast and gamma (mid-tones) settings after the programs had been optimized, indicating that the color masks sufficiently represented the pigments of interest, regardless of the image capture conditions. 

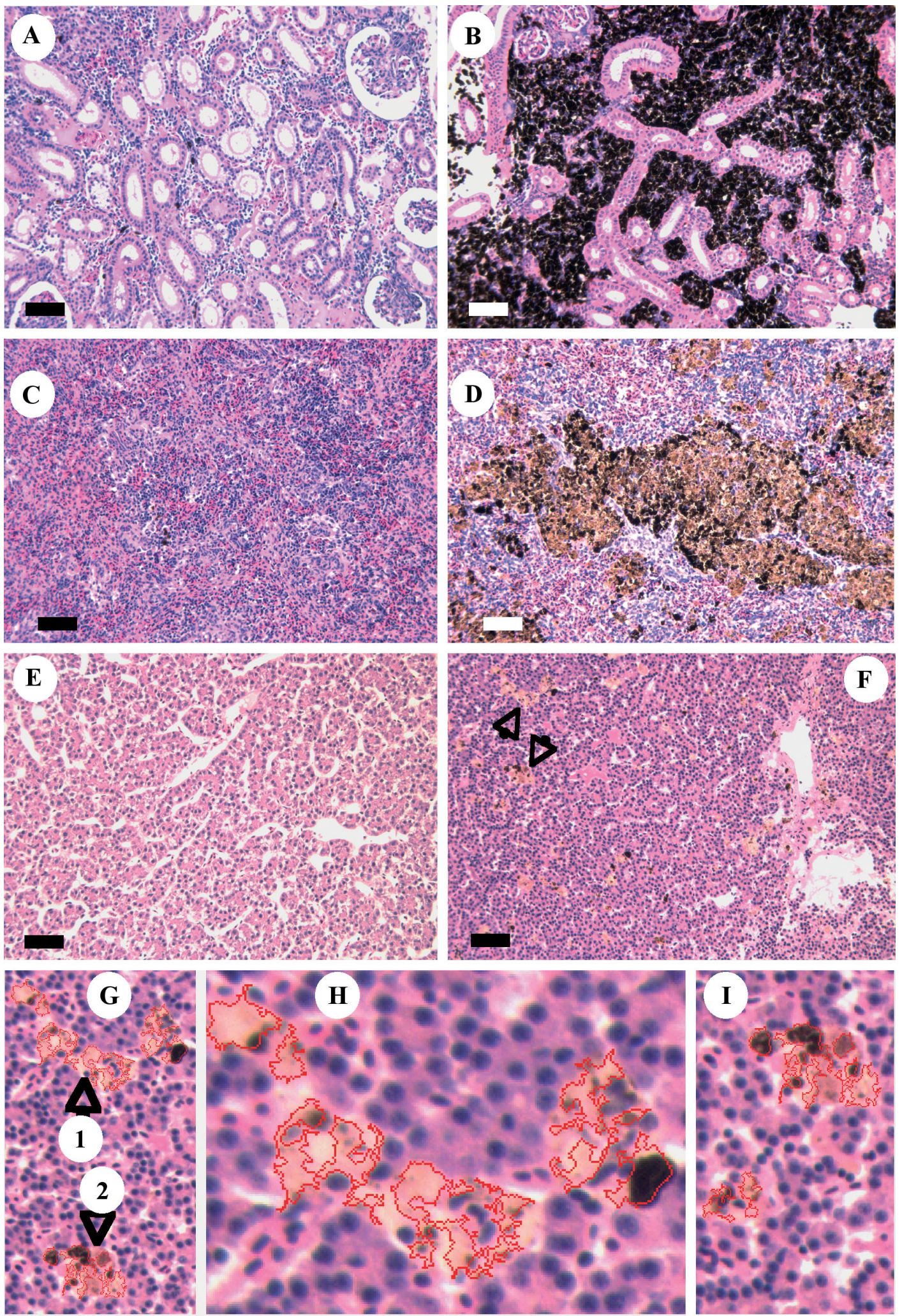

Fig. 2. Salvelinus fontinalis. Representative hematoxylin \& eosin stained organs showing (A to F) relative difference between fish with very few or no macrophage aggregates (MAs) and extensive accumulations of MAs and (G to I) high magnification hepatic MAs after software selected the pigments of interest. (A) Kidney with few MAs; (B) kidney with extensive MAs; (C) spleen with few MAs; (D) spleen with extensive MAs; (E) liver with no MAs; (F) liver with extensive MAs, arrowheads indicate MAs enlarged in $(G) ;(G)$ high magnification of liver MAs corresponding to MAs arrowed in $(F) ;(H) 2 \times$ magnification of MA corresponding to Arrow 1 in $(G)_{i}$ (I) $2 \times$ magnification of MA corresponding to Arrow 2 in (G). Outlined areas in (G) to (I) are computer output of delineated MAs based on pigment selection by the computer program (see 'Materials and methods') in the liver. Scale bars $=50 \mu \mathrm{m}$ 
Table 2. Salvelinus fontinalis and Oncorhynchus mykiss. Summary of regression statistics comparing macrophage aggregate (MA) pigment between organs. MA pigment data are arcsine square-root-transformed

\begin{tabular}{|lcccc|}
\hline Comparison & $F$ & $\mathrm{df}$ & $\mathrm{p}$-value & $\mathrm{R}^{2}$ \\
\hline S. fontinalis & & & & \\
$\quad$ Liver vs. kidney & 47.8 & 1,59 & $3.83 \times 10^{-9}$ & 0.45 \\
$\quad$ Liver vs. spleen & 13.0 & 1,59 & 0.0006 & 0.18 \\
$\quad$ Spleen vs. kidney & 12.1 & 1,59 & 0.001 & 0.17 \\
O. mykiss & & & & \\
$\quad$ Liver vs. kidney & 10.9 & 1,20 & 0.004 & 0.35 \\
$\quad$ Liver vs. spleen & 28.6 & 1,20 & $3.1 \times 10^{-5}$ & 0.59 \\
$\quad$ Spleen vs. kidney & 21.8 & 1,20 & 0.0001 & 0.52 \\
\hline
\end{tabular}

\section{Range of organ pigmentation and species differences}

Pigmented area was greatest in the kidney interstitium. The spleen displayed about half that of the kidney. The liver displayed the least pigmentation from all collection sites, with roughly 20 times less pigmentation than the kidney and 10 times less than the spleen (Fig. 1). When comparing between organs within a fish, pigments were positively correlated, i.e. if a relatively high percent area of pigmentation was found in the kidney, it was also observed in the spleen and the liver (Table 2). In terms of species differences, brook trout displayed significantly higher pigmentation than rainbow trout in all organs except the liver (Table 3). We were not able to control for a potential site effect because brook and rainbow trout were not captured from the same lakes or hatcheries, but age was not a factor.

\section{Effects of age, $K$, maturity and gender}

Fish ages ranged from 1 to $10 \mathrm{yr}$ in the combined data from all lakes and 1 to $4 \mathrm{yr}$ in fishes from the hatcheries. There was no difference in average age or $\mathrm{K}$ of brook trout between lakes ( $\mathrm{p}>0.05)$ (Table 1). Because we found no difference in average age or $\mathrm{K}$ between lakes, and no difference in pigmentation was observed in the age-matched hatchery and wild fish comparisons, all brook trout were grouped together and all rainbow trout were grouped together for regression analyses. Simple linear regression indicated that MA pigments were positively related to age and negatively related to $\mathrm{K}$ in all brook trout organs (Fig. 3, Table 4). In the rainbow trout, splenic, renal and hepatic MA pigments were significanty correlated with age, but only splenic and renal MA pigments were negatively related to $\mathrm{K}$ (Fig. 4, Table 4).

We tested if sexual maturation was correlated to kidney, liver and spleen MA pigmentation. Unlike age
Table 3. Salvelinus fontinalis and Oncorhynchus mykiss. Summary of statistics comparing macrophage aggregate (MA) pigment between the 2 species. Comparisons are average area occupied by MA pigments in kidney, liver and spleen. $\mathrm{N}=67$ $S$. fontinalis and 23 O. mykiss for liver and spleen and 68 S. fontinalis and 23 O. mykiss for kidney. Data (mean \pm SEM) are arcsine square-root-transformed to normalize distribution

\begin{tabular}{|lccc|}
\hline Organ & $\%$ area & Student's $t$ & $\mathrm{p}$-value \\
\hline S. fontinalis & & & \\
$\quad$ Kidney & $18.4 \pm 0.98$ & 3.67 & 0.0004 \\
Liver & $1.47 \pm 0.18$ & 0.86 & 0.39 \\
Spleen & $10.2 \pm 0.81$ & 5.35 & $3.08 \times 10^{-7}$ \\
O. mykiss & & & \\
Kidney & $11.7 \pm 1.28$ & 3.67 & 0.0004 \\
Liver & $1.14 \pm 0.38$ & 0.86 & 0.39 \\
Spleen & $2.6 \pm 0.45$ & 5.35 & $3.08 \times 10^{-7}$ \\
\hline
\end{tabular}

and $\mathrm{K}$, we detected no correlation ( $\mathrm{p}>0.05)$ between organ MA pigments and maturation stage (Stages 1 to 7). There were no statistical differences $(p>0.05)$ in maturation stage of the wild fishes between lakes, regardless of whether comparisons were made on the actual stages or on the maturation categories (immature, maturing, and mature). Therefore, we grouped the wild brook trout and tested each organ for correlation with maturation stage. Similarly, no gender effects were observed within each lake for all organs ( $p>$ 0.05). If gender-related differences in MA pigments existed, measures to test for between-lake differences

Table 4. Salvelinus fontinalis and Oncorhynchus mykiss. Summary of regression statistics comparing macrophage aggregate (MA) organ pigment versus age (yr) or condition factor $(\mathrm{K})$ calculated as in Table 1 . Age and $\mathrm{K}$ have a significant relationship with at least 1 organ in all fishes. MA data are arcsine square-root-transformed. No statistically significant relationships were detected between MA pigments and maturation state. FL: fork length

\begin{tabular}{|lcccc|}
\hline Comparison & $F$ & $\mathrm{df}$ & $\mathrm{p}$-value & $\mathrm{R}^{2}$ \\
\hline S. fontinalis & & & & \\
Pigment vs. age & & & & \\
$\quad$ Kidney & 44.2 & 1,60 & $9.93 \times 10^{-9}$ & 0.42 \\
$\quad$ Liver & 40.1 & 1,60 & $3.43 \times 10^{-8}$ & 0.40 \\
$\quad$ Spleen & 46.0 & 1,59 & $6.27 \times 10^{-9}$ & 0.44 \\
Pigment vs. K (FL) & & & & \\
$\quad$ Kidney & 38.1 & 1,61 & 0.0005 & 0.18 \\
Liver & 7.0 & 1,61 & 0.01 & 0.10 \\
$\quad$ Spleen & 38.1 & 1,60 & $6.38 \times 10^{-8}$ & 0.39 \\
& & & & \\
O. mykiss & & & & \\
Pigment vs. age & & & & \\
$\quad$ Kidney & 26.2 & 1,18 & $7.3 \times 10^{-5}$ & 0.59 \\
Liver & 7.8 & 1,19 & 0.01 & 0.29 \\
$\quad$ Spleen & 12.4 & 1,18 & 0.002 & 0.41 \\
Pigment vs. K (FL) & & & & \\
$\quad$ Kidney & 21.4 & 1,12 & 0.0006 & 0.64 \\
$\quad$ Liver & 0.84 & 1,12 & 0.38 & 0.07 \\
$\quad$ Spleen & 6.4 & 1,12 & 0.03 & 0.35 \\
\hline
\end{tabular}



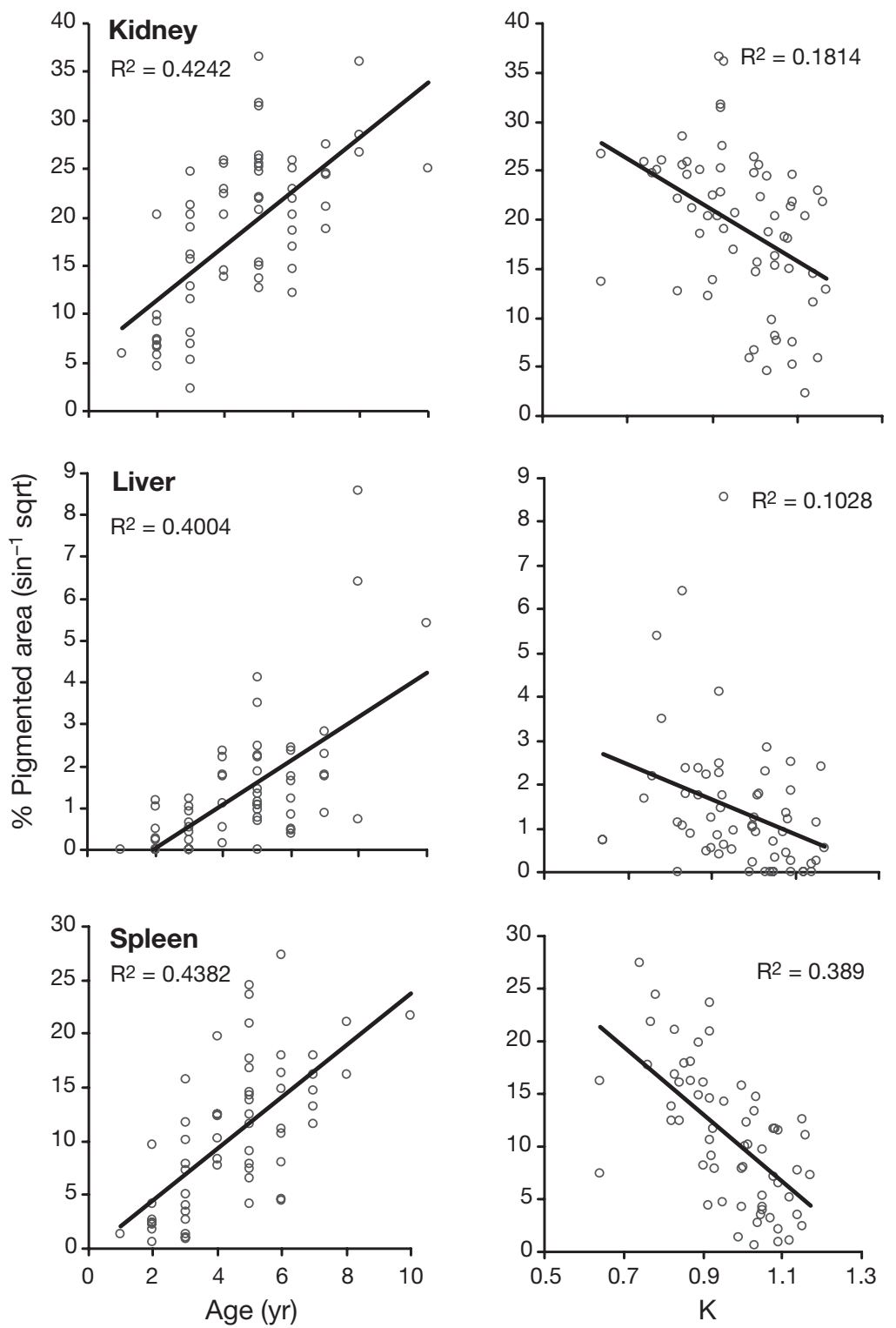

Fig. 3. Salvelinus fontinalis. Macrophage aggregate (MA) percent area occupied by pigments (arcsine square-root-transformed) versus age or condition factor (K) calculated from fork length (see Table 1 legend) in kidney, liver and spleen. Transformed percentages are average counts of MA pigmented areas of 4 images per organ per fish and lines are best fit from linear regression

would be confounded considering that skewed sexratios were observed at Pear and PJ lakes (Table 1). No noticeable MAs were observed in the gonads.

\section{Watershed effects}

We tested for differences in MA pigments between lakes with brook trout, and fish from Emerald Lake, Sequoia NP, had significantly more renal MA pigments than fish from any other lake. Fish from Pear Lake, Sequoia NP, had significantly more renal MA pigments than fish from Lone Pine Lake, Rocky Mountain NP $\left(F_{3,59}=7.9, \mathrm{p}=0.0001\right)$ (Fig. 5). In the spleen, brook trout from Sequoia NP displayed significantly more MA pigments than those from the other parks $\left(F_{3,59}=5.5, \mathrm{p}=0.002\right)$. No differences were detected in hepatic MA pigments between lakes. Comparison of MAs in age-matched wild and hatchery brook trout or rainbow trout indicated no difference in average pigmentation in any organ ( $p>0.05)$.

\section{Miscellaneous lesions and histological artifact}

In addition to analysis of MAs, several lesions and a single histological artifact were observed in both hatchery and wild fishes. Chronic interstitial nephritis comprising coalescing granulomas was observed in the renal interstitium of 1 brook trout from Emerald Lake, Sequoia NP (Fig. 6A). Gram and PAS stains did not reveal microorganisms in these lesions. Spiny objects, consistent with setae from a larval moth (order Lepidoptera) (Wood \& Yasutake 1956), were observed in the spleen and gonad of 3 brook trout from both lakes in Sequoia NP. In all cases, these objects were associated with chronic, focal inflammation and fibroplasia (Fig. 6B). Nephrocalcinosis was observed in the kidney of 1 brook trout from Wizard Falls Hatchery (Fig. 6C). Of the rainbow trout from Roaring River Hatchery, 55\% displayed light to heavy Nanophyetus salmincola metacercariae infections (Fig. 6D). Bile duct hyperplasia was found in the liver of a 1 yr old rainbow trout at Mills Lake, Rocky Mountain NP (Fig. 6E). These lesions were not associated with statistically significant differences in MAs when comparing age- and species-matched hatchery and wild fishes. We observed tissue shrinkage and fracture, resulting in regions of white space predominantly in the kidney (Fig. 6F).

\section{DISCUSSION}

The image analysis software we employed accurately and efficiently quantified the area occupied by MA pigments in the kidney, liver and spleen of brook 

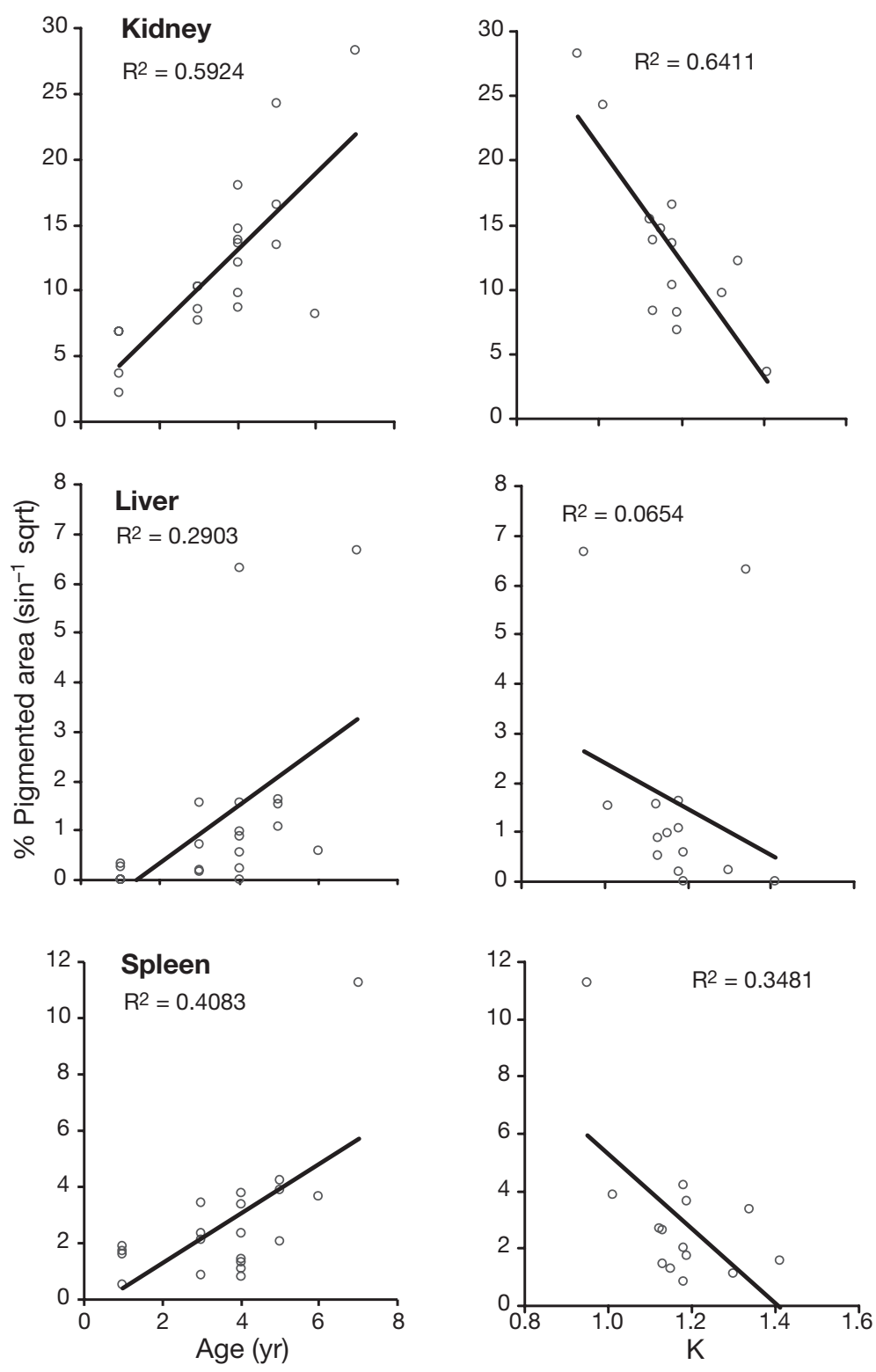

Fig. 4. Oncorhynchus mykiss. Macrophage aggregate percent area occupied by pigments (arcsine square-root-transformed) versus age or condition factor $(\mathrm{K})$ calculated from fork length in kidney, liver and spleen. Further details as in Fig. 3

and rainbow trout. Evaluation of MAs in salmonids has been largely ignored due, presumably, to difficulties in quantifying these poorly organized structures present in these fishes (Wolke 1992, Agius \& Roberts 2003). We addressed this problem using the area occupied by MA pigments rather than direct counts of MAs, and used image analysis to quantify the pigmented area. With this method, the definition of a MA is less critical, but similar information regarding MA pigments is obtained. The colors selected by the color masks ranged from gold to brown to black, precisely the colors representing MA pigments in hematoxylin and eosin stained sections. The color mask method we developed to automate pigment selection was twice as efficient as performing the pigment selection by hand. False positive selection of colors was not observed (i.e. dark blue was not confused with black), indicating that the color mask accurately distinguished between the MA pigments and colors induced by hematoxylin and eosin stains. More importantly, this method provides quantitatively rigorous data and objectively evaluates salmonid MAs.

Comparison of the subjectively evaluated MAs from the entire tissue sections with the results of the image analysis of area occupied by MAs in subsets of the tissue sections revealed a strong correlation. This indicated that the images (subsets) were accurate representations of the entire section. Our results indicate that quantitative pigment evaluation is ideal for salmonids, and potentially other fishes that do not display discrete, easily discernible MAs. Other investigators have used area occupied by MA pigment rather than number of aggregates $\mathrm{mm}^{-2}$. Using image analysis (NIH Image System Version 1.57), Mizuno et al. (2002) demonstrated that kidney melanin increased with starvation in masu salmon, and starvation has also been associated with increased numbers of MAs (Agius \& Roberts 1981). Also utilizing image analysis, Khan \& Nag (1993) noted increased splenic hemosiderin in longhorn sculpin Myoxocephalus octodecemspinosus, yellowfin sole Limanda aspersa, quillback rockfish Sebastes maliger and kelp greenling Hexagrammos decagrammus exposed to crude oil. Kranz (1989) quantified splenic hemosiderin in the dab L. limanda, which was more commonly found in fish with ulcerous livers than in fish that had recovered from the ulcer disease. Also in the dab, Bucke et al. (1992) found significantly reduced hemosiderin content at sites with the highest and the lowest levels of contaminated sediment; however, these authors recognized that the fish may have migrated between sites. Manual counting of MAs is potentially ambiguous in salmonids, depending on the definition of a MA, and is clearly time-consuming. For example, Agius \& Roberts (1981) reported hand-counting 250 to 800 and 500 to $2200 \mathrm{MAs} \mathrm{mm}^{-2}$ in the spleen and kidney, respectively, of rainbow trout. In many species, MAs form discrete aggregations and these data are best expressed as numbers $\mathrm{mm}^{-2}$ (Haensly et al. 1982, Brown \& George 


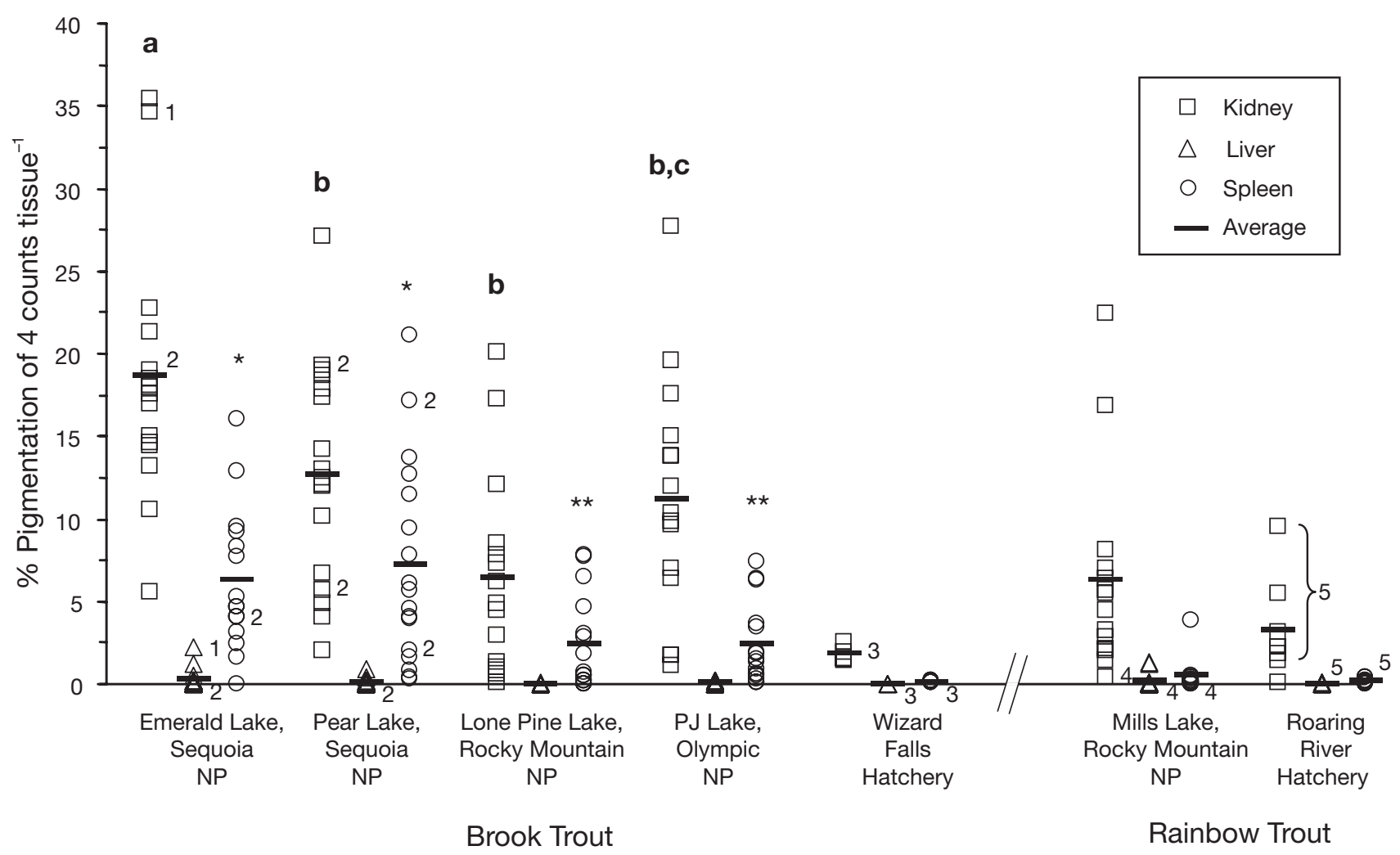

Fig 5. Salvelinus fontinalis and Oncorhynchus mykiss. Macrophage aggregate pigmented area data from individuals and averages from lakes in national parks (NP) and hatcheries. Different letters or asterisks for $S$. fontinalis kidney or spleen indicate statistical differences in average pigmentation within tissues between lakes. $(p<0.05)$. No difference was detected between agematched hatchery and wild $S$. fontinalis or age-matched hatchery and wild $O$. mykiss. ANOVA indicated no difference ( $p>0.05)$ in average age or condition factor between fishes in the lakes. Superscripts indicate individual fish: ${ }^{1} \mathrm{chronic}$ interstitial nephritis;

${ }^{2}$ foreign body/spines; ${ }^{3}$ nephrocalcinosis; ${ }^{4}$ liver bile duct hyperplasia; ${ }^{5}$ Nanophyetus salmincola

1985, Blazer et al. 1987, George-Nascimento et al. 2000, Manera et al. 2000, Fournie et al. 2001, Khan 2003) or percent occurrence of MAs (Patiño et al. 2003, Capps et al. 2004), or evaluated by relative scoring of MA density accumulation (Vethaak \& Wester 1996, Marty et al. 1999, Fournie et al. 2001).

Our results indicate that the posterior kidney, liver and spleen can all be used for MA analysis in salmonids, given that MA pigmentation was positively correlated among all 3 organs within individual fish. In other words, increased pigmentation in any of the organs examined corresponded to similar increases in the other organs. The kidney, liver and/or spleen have been used as indicator organs of non-age associated MA accumulations in other fishes, such as studies on contaminant exposure (e.g. Khan \& Kiceniuk 1984, Blazer et al. 1987, Pulsford et al. 1992, Elston et al. 1997, Mercer et al. 1997, George-Nascimento et al. 2000, Manera et al. 2000, Fournie et al. 2001, Khan 2003). It should be noted, however, that the presence of MAs is not entirely indicative of contaminant exposure. MAs in the spleen and liver have been shown to diminish or disappear during contaminant exposure
(Matthiessen \& Roberts 1982, Payne \& Fancey 1989, Spazier et al. 1992), as has the phagocytic activity of individual macrophages in the kidney (Weeks \& Warriner 1984). Identifying the relationships of MAs with specific contaminants within the same fish, rather than at the population level within a watershed, would help clarify the role of MAs as a biomarker for contaminant exposure.

We found significant positive correlations with age, in support of previous work (Agius 1981, Brown \& George 1985, Blazer et al. 1987, Vethaak \& Wester 1996) and negative correlations to $K$, also supporting other investigations (Blazer et al. 1987, Vethaak \& Wester 1996). In both brook and rainbow trout, the liver showed significant but relatively weak correlations to age and $\mathrm{K}$, possibly indicating that the liver might be an appropriate indicator organ for other factors affecting MAs. In the largemouth bass Micropterus salmoides, the liver had slightly better correlations of MAs with age and fish condition than the spleen (Blazer et al. 1987), indicating that the liver may be a better indicator of age associated pigmentation for this species. Although the mechanisms for age associated 

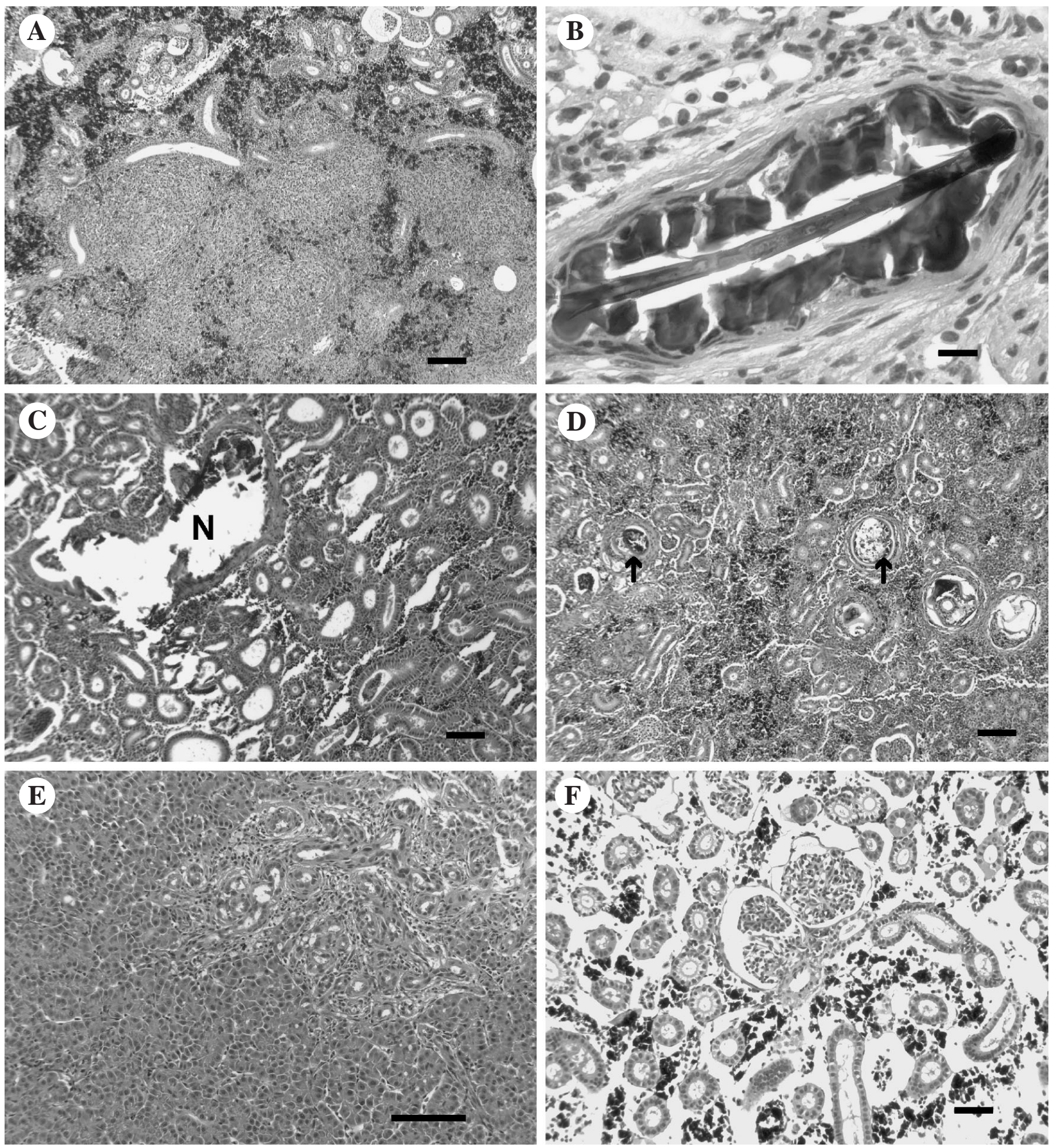

Fig. 6. Salvelinus fontinalis and Oncorhynchus mykiss. Histological changes and artifact in fishes from high mountain lakes and hatcheries. Hematoxylin \& eosin. (A) Coalescing granulomas in renal interstitum of brook trout; (B) spiny object, possibly setae of larval moth (order Lepidoptera) surrounded by chronic inflammation and fibroplasia in gonad of $S$. fontinalis; (C) dilated tubule with basophilic debris (N) consistent with nephrocalcinosis in kidney of hatchery-reared $S$. fontinalis; (D) metacercariae of Nanophyetus salmincola (arrows) in kidney of hatcheryreared O. mykiss; (E) liver with region of bile duct hyperplasia in an O. mykiss; (F) posterior kidney showing prominent post-mortem organ shrinkage due to histological processing. Scale bar $=10 \mu \mathrm{m}$ in (B), $100 \mu \mathrm{m}$ elsewhere 
accumulation of MAs have not been determined, these focal accumulations may increase with necrosis or apoptosis associated with aging. The negative correlations between MAs and fish condition may be a function of poor nutrition, given that MA counts or pigmentation increase after starvation (Agius \& Roberts 1981, Mizuno et al. 2002) and starvation reduces K (Morgan \& Metcalfe 2001). In the brook trout, splenic MA pigment correlated best with both age and $K$, while the kidney MA pigment correlated strongest with age and $\mathrm{K}$ in the rainbow trout. The latter agrees with the studies of Agius (1981) and Agius \& Roberts (1981), in which the kidney showed the widest range in numbers of MAs $\mathrm{mm}^{-2}$ associated with age or starvation in rainbow trout. However, we did not quantify number of MAs $\mathrm{mm}^{-2}$, and thus our results are not directly comparable with these studies. We observed no relationships in any organ between MAs and gender or maturity. This is consistent with the findings of Brown \& George (1985) in yellow perch Perca flavescens and Blazer et al. (1987) in largemouth bass Micropterus salmoides for gender. However, Elston et al. (1997) determined that sexual maturity was positively correlated to liver MAs in Pacific herring Clupea pallasi. The salmonids used in the present study are iteroparous and seasonal maturation cycles involve the mobilization of energy stores to prepare the gonads for reproduction. Our finding of no sexual maturation effect indicates that successive reproductive cycles do not induce excessive pigmentation characteristic of lipid breakdown. Alternatively, in the sexually mature individuals, it is possible that ceroid/lipofuscin occupied a higher proportion of the area than the other pigments.

We have not found an explanation for between-lake differences observed in the present study; they could not be attributed to age, $\mathrm{K}$, gender or stage of maturation, as there were no statistical differences in these parameters between the lakes. For example, the sex distribution was highly skewed toward males at Pear Lake, Sequoia NP, but there were no differences in MAs between the sexes. All fishes were sampled during the months of August and September, and thus seasonality was not a factor.

We observed greater pigmented area in the brook trout than in the rainbow trout in the kidney and spleen but not in the liver. However, it is possible that these differences were due to site effects, as the brook and rainbow trout were not captured from the same lake or acquired from the same hatchery. Interspecific differences in MA concentrations have been observed in fishes collected from the same watershed (Zuasti et al. 1990, Facey et al. 1999). In contrast, the yellowtail flounder Limanda ferruginea, gray sole Glyptocephalus cynoglossus, and winter flounder Pleuronectes americanus were assessed for MAs and showed significant differences between contaminated and reference sites, but no difference in spleen or kidney MAs between species within a given site (Khan 2003).

It appeared that hatchery fishes displayed less MA pigmentation than the wild fishes, but no differences were detected when comparisons were made on an age-matched basis. Mizuno et al. (2002) concluded that starved hatchery and wild masu salmon did not differ in kidney melanization. Some researchers have suggested that wild and hatchery fish display differential responses to stressors (Woodward \& Strange 1987 , Fleming \& Gross 1992, Lepage et al. 2000). Perhaps the suggestion that wild fishes respond to stress differently than hatchery fishes do not apply when MAs are used as stress indicators. Both wild and captive fishes are exposed to stressors, although the stressors themselves may be different (St.-Hilaire et al. 1998).

Helminth infections in trout did not correlate with increases in MA pigments. Over half of the hatchery rainbow trout had varying levels of Nanophyetus salmincola infections in the kidney, yet no difference in MA pigments were detected compared to wild rainbow trout. This indicates, at least for this study, that the metacercariae of $N$. salmincola are not associated with an increase in MAs. Similarly, the yellow perch Perca flavescens exhibited no relationship between MAs and encysted metacercariae of Neascus sp. or the larval tapeworm Proteocephalus ambloplitis in the liver (Brown \& George 1985). However, MAs congregate around the spores of various Myxobolus spp. in the spleen and kidney of the chub Leuciscus cephalus and may be centers of spore destruction in the hematopoietic organs (Dyková 1984, Holzer \& Schachner 1984). The chronic nephritis with coalescing granulomas observed in 1 brook trout was consistent with bacterial kidney disease caused by Renibacterium salmoninarum, but Gram or PAS stains did not reveal microorganisms.

The gonads and spleens of several fishes from Sequoia NP contained peculiar foreign bodies comprising barbed spines. These spines resembled the setae of larval moths (order Lepidoptera) which caused lesions in $13 \%$ of coho salmon Oncorhynchus kisutch captured on the Olympic Peninsula, Washington (Wood \& Yasutake 1956). The setae observed in our study probably migrated through the gastro-intestinal tract, pierced numerous organs, and induced a chronic inflammatory response similar to that observed by Wood \& Yasutake (1956). As with the Nanophyetus salmincola infections, these spines were not associated with focal accumulations of MAs.

In summary, we have demonstrated that quantification of pigments associated with MAs in the salmonid kidney, liver and spleen is efficient and accurate with image analysis, and that quantitative assessment compares well with subjective evaluation. Our results also 
indicate that salmonid MAs behave similarly to the more derived fishes, with significant correlations with age and $K$, but no relationship to sex or maturity. We assume that MAs may also change after contaminant exposure, similar to more derived fishes. We will be examining the relationship between MA pigment and contaminants as part of the Western Airborne Contaminants Assessment Project.

Acknowledgements. This work is part of WACAP (Western Airborne Contaminants Assessment Project), a collaborative venture among the National Park Service, the Environmental Protection Agency, the US Geological Survey, Oregon State University, University of Washington, and the USDA Forest Service. It was funded primarily through cooperative and interagency agreements with the National Park Service, and also included in-kind contributions from all of the project partners. Further information about WACAP can be found on the WACAP web site at: www2.nature.nps.gov/air/Studies/ air_toxics/wacap.htm. This document has been subjected to appropriate institutional peer review (EPA and Oregon State University) and/or administrative review and approved for publication. Mention of trade names or commercial products does not constitute endorsement or recommendation for use. We thank Dr. L. Curtis, Department of Environmental and Molecular Toxicology, Oregon State University, for a critical review of the manuscript, members of the WACAP team for sample collection, and the ODFW for hatchery fish donations.

\section{LITERATURE CITED}

Agius C (1981) Preliminary studies on the ontogeny of the melano-macrophages of teleost haemopoietic tissues and age-related changes. Dev Comp Immunol 5:597-606

Agius C, Roberts RJ (1981) Effects of starvation on the melano-macrophage centres of fish. J Fish Biol 19:161-169

Agius C, Roberts RJ (2003) Melano-macrophage centers and their role in fish pathology. J Fish Dis 26:499-509

Blazer VS (2002) Histopathological assessment of gonadal tissue in wild fishes. Fish Physiol Biochem 26:85-101

Blazer VS, Wolke RE, Brown J, Powell CA (1987) Piscine macrophage aggregate parameters as health monitors: effect of age, sex, relative weight, season, and site quality in largemouth bass (Micropterus salmoides). Aquat Toxicol (NY) 10:199-215

Blazer VS, Facey DE, Fournie JW, Courtney LA, Summers JK (1994) Macrophage aggregates as indicators of environmental stress. In: Stolen JS, Fletcher TC (eds) Modulators of fish immune responses, Vol 1. SOS Publications, Fair Haven, NJ, p 168-185

Blazer VS, Fournie JW, Weeks-Perkins BA (1997) Macrophage aggregates: biomarker for immune function in fish? In: Dwyer FJ, Doane TR, Hinman ML (eds) Environmental toxicology and risk assessment: modeling risk assessment, Vol 6. American Society for Testing and Materials, West Conshohocken, PA, p 360-375

Brown CL, George CJ (1985) Age-dependent accumulation of macrophage aggregates in the yellow perch, Perca flavescens (Mitchill). J Fish Dis 8:135-138

Bucke D, Vethaak AD, Lang T (1992) Quantitative assessment of melanomacrophage centres (MMCs) in dab Limanda limanda along a pollution transect in the German Bight. Mar Ecol Prog Ser 91:193-196
Capps T, Mukhi S, Rinchard JJ, Theodorakis CW, Blazer VS, Patiño R (2004) Exposure to perchlorate induces the formation of macrophage aggregates in the trunk kidney of zebrafish and mosquitofish. J Aquat Anim Health 16: 145-151

Dyková I (1984) The role of melanomacrophage centres in the tissue reaction to myxosporean infections of fishes. Bull Eur Assoc Fish Pathol 4:65

Elston RA, Drum AS, Pearson WH, Parker K (1997) Health and condition of Pacific herring (Clupea pallasi) from Prince William Sound, Alaska, 1994. Dis Aquat Org 31: 109-126

Facey DE, Leclerc C, Dunbar D, Arruda D, Pyzocha L, Blazer V (1999) Physiological indicators of stress among fishes from contaminated areas of Lake Champlain. In: Manley TO, Manley PL (eds) Lake Champlain in transition: from research toward restoration water science and application, Vol 1. American Geophysical Union, Washington, DC, p 349-359

Fleming IA, Gross MR (1992) Reproductive behavior of hatchery and wild coho salmon (Oncorhynchus kisutch): does it differ? Aquaculture 103:101-121

Fournie JW, Summers JK, Courtney LA, Engle VD, Blazer VS (2001) Utility of splenic macrophage aggregates as an indicator of fish exposure to degraded environments. J Aquat Anim Health 13:105-116

George-Nascimento M, Khan RA, Garcias F, Lobes V, Murñoz G, Valdebenito V (2000) Impaired health in flounder, Paralichthys spp. inhabiting coastal Chile. Bull Environ Contam Toxicol 64:184-190

Haensly WE, Neff JM, Sharp JR, Morris AC, Bedgood MF, Boem PD (1982) Histopathology of Pleuronectes platessa L. from Aber Wrac'h and Aber Benoit, Brittany, France: long-term effects of the Amoco Cadiz oil spill. J Fish Dis 5: 365-391

Hall DL (1991) Age validation and aging methods for stunted brook trout. Trans Am Fish Soc 120:644-649

Holzer AS, Schachner O (1984) Myxosporidia and macrophage centres in chub (Leuciscus cephalus) - quantitative interactions focus on Myxobolus cyprini. Parasitology 122: $55-62$

Khan RA (2003) Health of flatfish from localities in Placentia Bay, Newfoundland, contaminated with petroleum and PCBs. Arch Environ Contam Toxicol 44:485-492

Khan RA, Kiceniuk J (1984) Histopathological effects of crude oil on Atlantic cod following chronic exposure. Can J Zool 62:2038-2043

Khan RA, Nag K (1993) Estimation of hemosiderosis in seabirds and fish exposed to petroleum. Bull Environ Contam Toxicol 50:125-131

Kranz H (1989) Changes in splenic melano-macrophage centres of dab Limanda limanda during and after infection with ulcer disease. Dis Aquat Org 6:167-173

Lepage O, Øverli Ø, Petersson E, Jävi T, Winberg S (2000) Differential stress coping in wild and domesticated sea trout. Brain Behav Evol 56:259-268

Manera M, Serra R, Isani G, Carpené E (2000) Macrophage aggregates in gilthead sea bream fed copper, iron and zinc enriched diets. J Fish Biol 57:457-465

Marty GD, Okihiro MS, Brown ED, Hanes D, Hinton DE (1999) Histopathology of adult Pacific herring in the Prince William Sound, Alaska, after the Exxon Valdez oil spill. Can J Fish Aquat Sci 56:491-426

Matthiessen P, Roberts RJ (1982) Histopathological changes in the liver and brain of fish exposed to endosulfan insecticide during tsetse fly control operations in Botswana. J Fish Dis 5:153-159 
Mercer IRG, Barker DE, Khan RA (1997) Stress-related changes in cunner, Tautogolabrus adspersus living near a paper mill. Bull Environ Contamin Toxicol 58:442-447

Mizuno SN, Misaka N, Miyakoshi Y, Takeuchi K, Kasahara N (2002) Effects of starvation on melano-macrophages in the kidney of masu salmon (Oncorhynchus masou). Aquaculture 209:247-255

Morgan IJ, Metcalfe NB (2001) The influence of energetic requirements on the preferred temperature of overwintering juvenile Atlantic salmon (Salmo salar). Can J Fish Aquat Sci 58:762-768

Patiño R, Goodbred SL, Draugelis-Dale R, Barry CE, Foott JS, Wainscott MR, Gross TS, Covay KJ (2003) Morphometric and histopathological parameters of gonadal development in adult common carp from contaminated and reference sites in Lake Mead, Nevada. J Aquat Anim Health 15: $55-68$

Payne JF, Fancey LF (1989) Effect of polycyclic aromatic hydrocarbons on immune response in fish: changes in melanomacrophage centers in flounder (Pseudopleuronectes americanus) exposed to hydrocarbon-contaminated sediments. Mar Environ Res 28:431-435

Pulsford AL, Ryan KP, Nott JA (1992) Metals and melanomacrophages in flounder, Platichthys flesus, spleen and kidney. J Mar Biol Assoc UK 72:483-498

Spazier E, Storch V, Braunbeck T (1992) Cytopathology of spleen in eel Anguilla anguilla exposed to a chemical spill in Rhine River. Dis Aquat Org 14:1-22

St.-Hilaire S, Kent ML, Iwama GK (1998) Factors affecting the

Editorial responsibility: Otto Kinne (Managing Editor),

Oldendorf/Luhe, Germany health of farmed and wild fish populations: a perspective from British Columbia. Canadian Stock Assessment Secretariat Research Document 1998/168

Van Eenennaam JP, Doroshov SI (1998) Effects of age and body size on gonadal development of Atlantic sturgeon. J Fish Biol 53:624-637

Vethaak AD, Wester PW (1996) Diseases of flounder Platichthys flesus in Dutch coastal and estuarine waters, with particular reference to environmental stress factors. II. Liver histopathology. Dis Aquat Org 26:99-116

Vogelbein WK, Fournie JW, Overstreet RM (1987) Sequential development and morphology of experimentally induced melano-macrophage centers in Rivulus marmoratus. J Fish Biol 31(Suppl A):145-153

Weeks BA, Warinner E (1984) Effects of toxic chemicals on macrophage phagocytosis in two estuarine fishes. Mar Environ Res 14:327-335

Wolke RE (1992) Piscine macrophage aggregates: a review. Annu Rev Fish Dis 2:91-108

Wood EM, Yasutake WT (1956) Tissue damage in salmonids caused by Halisidota argentata Packard. J Parasitol 42: $544-546$

Woodward CC, Strange RJ (1987) Physiological stress responses in wild and hatchery-reared rainbow trout. Trans Am Fish Soc 116:574-579

Zuasti A, Ferrer C, Aroca P, Solano F (1990) Distribution of extracutaneous melanin pigment in Sparus auratus, Mugil cephalus, and Dicentrarchus labrax (Pisces, Teleostei). Pigm Cell Res 3:126-131

Submitted: May 12, 2005; Accepted: July 28, 2005

Proofs received from author(s): January 17, 2006 